\title{
Characterization of benzil bis o-phenylenediamine based macro cyclic Co-complexes using x-ray spectroscopic techniques (XRD and EXAFS)
}

\author{
Sadique Mohammad ${ }^{1}$, A. Mishra ${ }^{2}$, P. Sharma ${ }^{3 *}$, S. Patidar ${ }^{4}$ \\ ${ }^{1}$ School of Physics, DAVV, Indore (M.P), India \\ ${ }^{2}$ School of Physics, DAVV, Indore (M.P), India \\ ${ }^{3}$ Dept. of Physics, Govt. Holkar Science College, Indore (M.P), India \\ ${ }^{4}$ School of Physics, DAVV, Indore (M.P), India \\ *Corresponding Author: psharma29762@gmail.com
}

Available online at: www.isroset.org

Received 30/Dec/2017, Revised 15/Jan/2018, Accepted 29/Jan/2018, Online 28/Feb/2018

\begin{abstract}
Schiff base condensation of benzil bis o-phenylenediamine with acetophenone, benzaldehyde and P-cloro benzaldehyde and its Cobalt complexes were synthesized. Preparation of the free ligands was accomplished by refluxing benzyl with o-phenylenediamine in 1:10 mole ratio in methanol. The XRD and EXAFS characterization of benzil bis ophenylenediamine based macro cyclic complexes of Cobalt was undertaken. From the result of investigations of XRD particle size and lattice parameter have been estimated .The XRD analysis revealed the crystalline nature of all complexes. EXAFS spectra have been recorded at the K-edge of Co using the dispersive EXAFS beam line at $2.5 \mathrm{GeV}$ Indus-2 synchrotron radiation source RRCAT, Indore ,India .From the fine structure data the average metal-ligand bond distances have been estimated. Bond lengths for Co-complexes have been determined with the help of Levy's, LSS, Lytle's, Fourier transform methods.
\end{abstract}

Keywords-o-phenylenediamine, acetophenone

\section{INTRODUCTION}

Schiff bases of o-phenylenediamine and its complexes have a variety of application including clinical, analytical and biological. Schiff bases derived from the salicylaldehydes are well known as polydentate ligands coordinating in neutral forms. [1,2].X-ray diffraction XRD technique is used to know crystal structure, lattice parameter, particle size and orientation of polycrystals[3].EXAFS spectroscopy provides information about the chemical environment of a single element in terms of the number and type of its neighbours, inter-atomic distances and structural disorders using Fourier transform of EXAFS spectrum.[4,5] The bond lengths can also be determined by three other methods ,namely Levy's , Lytle's and Lytle, Sayers and Stern's[LSS]methods. The LSS method gives phase uncorrected bond length of first shell [6,7].Fourier transform and LSS method both provides phase uncorrected bond lengths. In the present work Schiff base condensation of benzil bis o-phenylenediamine with acetophenone, p-chlorobenzaldehyde and benzaldehyde and its Co complexes were synthesised. Schiff base condensation of bis o-phenylenediamine with suitable aldehydes and ketones would form a macro cyclic and macro acyclic molecules which will have more number of nitrogen atoms, and this will behave as better coordinating ligands for variety of metal atoms [8].

Hence the synthesis and characterisation of Characterization of benzil bis o-phenylenediamine based macro cyclic Cocomplexes was undertaken. Paper has been written into four distinct sections, Introduction, Methodology, Results and discussion and Conclusions. Introduction section contains a brief review of literature survey related to the present work, motivation and scope of the work. The section on methodology contains sample preparation and measurements techniques. Results and discussion section deals with the results, analysis and discussion. Conclusion part narrates the major conclusions drawn from the results.

\section{Methodology}

\section{Preparation of benzil bis o-phenylenediamine}

Benzil (10.5 g, $50 \mathrm{mmol})$ was dissolved in $100 \mathrm{ml}$ of methanol and o-phenylenediamine $(54.05 \mathrm{~g}, 500 \mathrm{mmol})$ was added to it .The resulting solution was refluxed for $3 \mathrm{~h}$ and then it was left in the air. After $20 \mathrm{~h}$ the precipitated white 
microcrystalline compound was filtered off and washed with $100 \mathrm{~mL}$ of water. The compound was dried in air.

\section{Synthesis of macro cyclic complexes:}

\section{Synthesis of $\left[\mathrm{Co}\left(\mathrm{C66H56N8}_{)}\right] \mathrm{Cl}_{2}\right.$ or $(\mathrm{Co}-\mathrm{AP})$}

Acetophenone $(1.2 \mathrm{~g}, 10 \mathrm{mmol})$ was added to a solution of $\mathrm{CoCl} 2(0.55 \mathrm{~g}, 5 \mathrm{mmol})$ in $15 \mathrm{~mL}$ of methanol. To this solution, benzil bis o-phenylenediamine $(3.9 \mathrm{~g}, 10 \mathrm{mmol})$ was added. The solution was stirred for $1 \mathrm{~h}$ and 30 minutes at room temperature. Finally the precipitates were dried in air.

\section{Synthesis of $[\mathrm{Co}(\mathrm{C64H52N8})] \mathrm{Cl}_{2}$ or $\quad(\mathrm{Co}-\mathrm{BZ})$}

To a solution of $\mathrm{CoCl} 2(0.11 \mathrm{~g}, 1 \mathrm{mmol})$ in $3 \mathrm{~mL}$ of methanol, benzaldehyde (318.39 $\mathrm{mg}, 3 \mathrm{mmol})$ was added. To this solution benzil bis o-phenylenediamine $(1.1 \mathrm{~g}, 3 \mathrm{mmol})$ was added. The reaction was refluxed for $2 \mathrm{~h}$ and left for precipitation.

\section{Synthesis of $[\mathrm{Co}(\mathrm{C54H50N8})] \mathrm{Cl}_{2}$ or $(\mathrm{Co}-\mathrm{P})$}

To a vigorously stirred solution of $\mathrm{CoCl} 2(0.16 \mathrm{~g}, 1.5 \mathrm{mmol})$ in $4.5 \mathrm{~mL}$ of methanol, p-chlorobenzaldehyde $(0.4 \mathrm{~g}, 3 \mathrm{mmol})$ was added. To this solution, benzil bis o-phenylenediamine $(1.1 \mathrm{~g}, 3 \mathrm{mmol})$ was added. The reaction mixture was stirred for $2 \mathrm{~h}$ and left for precipitation.

X-ray diffraction pattern have been recorded by Bruker D8 advance diffract meter at IUC, Indore The X-ray absorption spectra at the K-edge of cobalt of these complexes have been recorded at BL-8 Dispersive EXAFS beamline at the 2.5GeV INDUS-2 Synchrotron Source, Raja Ramanna Centre for Advanced Technology (RRCAT), Indore, India .

The transmitted beam intensity from the sample is recorded on a position sensitive CCD detector. The intensities IO and It, are obtained as the CCD outputs without and with the sample respectively. Using the relation, It $=\mathrm{I}_{0} \mathrm{e}^{-\mu \mathrm{x}}$, where $\mu$ is the absorption coefficient and $\mathrm{x}$ is the thickness of the absorber. The experiment data have been analysed using software Origin 9 and Athena 0.80.056. First, the normalized $\mu(\mathrm{E})$ versus $\mathrm{E}$ spectra are obtained, then $\chi(\mathrm{k})$ versus $\mathrm{k}$ spectra are obtained, and finally, the Fourier transforms of $\chi(\mathrm{k})$ versus $\mathrm{k}$ spectra are obtained.

\section{RESULTS AND DISCUSSION}

The crystal structure and lattice parameter were analysed by Bragg's law, $2 \mathrm{~d} \sin \theta=\mathrm{n} \lambda$ and particle size is calculated by Debye Scherer's formula, $\mathrm{t}=0.9 \lambda / \mathrm{B} \cos \theta$. The XRD pattern of the complexes is reported in figure 1. The particle size and lattice parameter are shown in table1. The X-ray analysis shows the complexes are crystalline in nature.

The normalized X-ray absorption spectra of Co-complexes are shown in figure 2 (a). The EXAFS spectra converted into $\mathrm{k}$-space have been given in figure 2(b). A Fourier transform is applied to these data to convert into $\mathrm{R}$-space is shown in figure 2(c). The bond lengths of Co-complexes were calculated using Levy's method, the slope of channel No. $n$ verses wave vector $\mathrm{k}$ curves by $\operatorname{LSS}$ method [9, 10]. The slope of energy level Q verses energy E curves have been used to evaluate the bond lengths by Lytle's method [11]. The magnitudes of Fourier transform are shown in figure 2.

The phase-uncorrected bond length has been determined by the Fourier transform technique. Before Fourier transform technique was formulated, the bond lengths were extracted from the EXAFS data by the three graphical methods. Thus, the bond lengths have been determined for the Co-complexes with help of Levy's, Lytle's and Lytle, Sayers and Stern (LSS) methods and the results are given in Table 2.

\section{CONCLUSION}

As is evident from the analysis of X-ray diffraction pattern, one can conclude that the samples exhibit crystalline nature and shape of unit cell is simple cubic. From the positions of the EXAFS maxima and minima, the bond lengths of the Cocomplexes has been determined by three different methods viz. Levy's, Lytle's and LSS methods. From the Fourier transforms of the EXAFS spectra, the bond length (uncorrected for phase shift) has been determined. It has been observed that the values of the phase-uncorrected bond length, i.e.R1- $\alpha 1$ as determined from LSS method and that determined from the Fourier transformation method, are in good agreement with each other.

\begin{tabular}{|l|l|l|l|}
\hline S. No. & Name of Complexes & Particle size $(\mathrm{nm})$ & $\begin{array}{l}\text { Lattice parameter } \\
(\AA)\end{array}$ \\
\hline 1 & {$\left[\mathrm{Co}\left(\mathrm{C}_{64} \mathrm{H}_{52} \mathrm{~N}_{8}\right)\right] \mathrm{Cl}_{2} / \mathrm{Co}-\mathrm{BZ}$} & 81.85 & 5.43 \\
\hline 2 & {$\left[\mathrm{Co}\left(\mathrm{C}_{54} \mathrm{H}_{50} \mathrm{~N}_{8}\right)\right] \mathrm{Cl}_{2} / \mathrm{Co}-\mathrm{P}$} & 69.85 & 5.36 \\
\hline 3 & {$\left[\mathrm{Co}\left(\mathrm{C}_{66} \mathrm{H}_{56} \mathrm{~N}_{8}\right)\right] \mathrm{Cl}_{2} / \mathrm{Co}-\mathrm{AP}$} & 73.47 & 5.55 \\
\hline
\end{tabular}


Table 2

\begin{tabular}{|c|c|c|c|c|c|c|}
\hline \multirow[t]{2}{*}{ S.No. } & \multicolumn{2}{|c|}{ Name of Complexes } & \multicolumn{2}{|c|}{ Phase corrected } & \multicolumn{2}{|c|}{ Phase uncorrected } \\
\hline & & & Levy's method $\mathbf{R}_{1}$ & Lytle method $R_{s}$ & L.S.S.method R1-a1 & $\begin{array}{c}\text { F.T. } \\
\text { method R }\end{array}$ \\
\hline 1. & {$\left[\mathrm{Co}\left(\mathrm{C}_{64} \mathrm{H}_{52} \mathrm{~N}_{8}\right)\right] \mathrm{Cl}_{2}$} & Co-AP & 2.46 & 1.66 & 1.52 & 1.3 \\
\hline 2. & {$\left[\mathrm{Co}\left(\mathrm{C}_{66} \mathrm{H}_{56} \mathrm{~N}_{8}\right)\right] \mathrm{Cl}_{2}$} & Co-BZ & 2.43 & 1.79 & 1.43 & 1.58 \\
\hline 3. & {$\left[\mathrm{Co}\left(\mathrm{C}_{54} \mathrm{H}_{50} \mathrm{~N}_{8}\right)\right] \mathrm{Cl}_{2}$} & Co-P & 2.55 & 1.80 & 1.46 & 1.62 \\
\hline
\end{tabular}

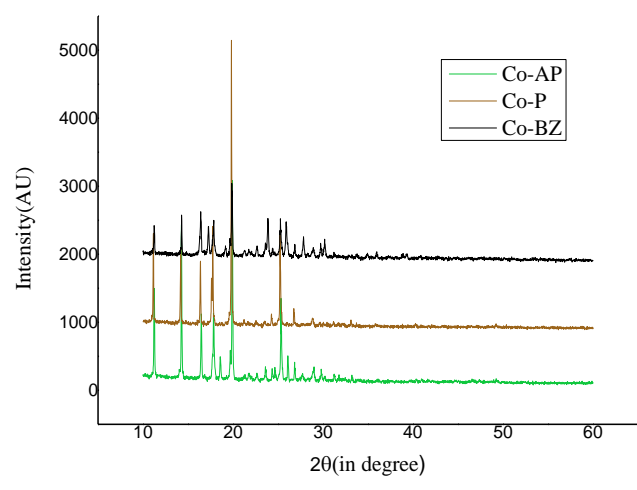

Figure 1. XRD pattern

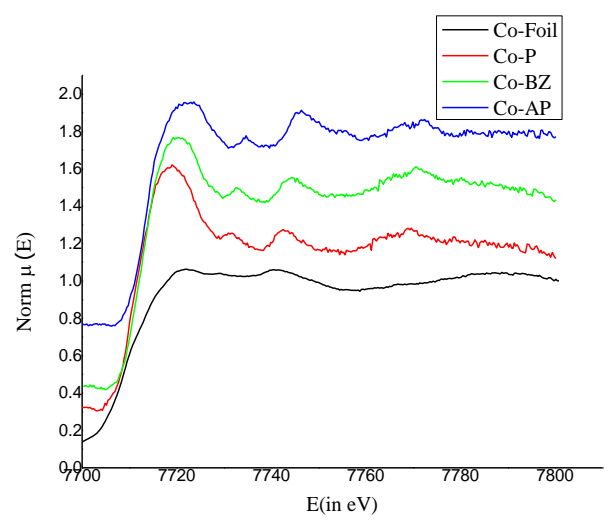

(a)

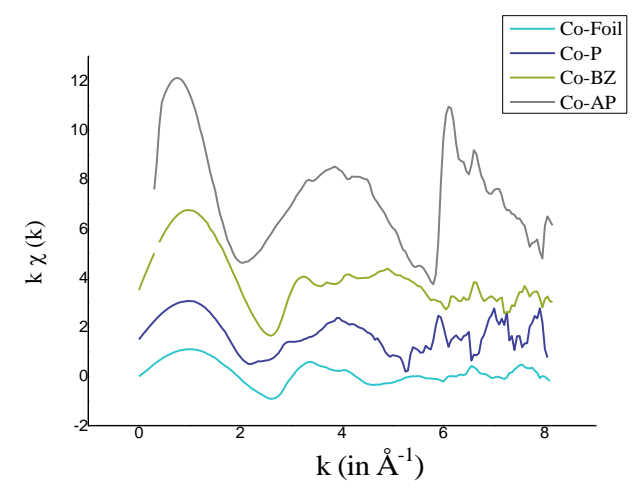

(b)

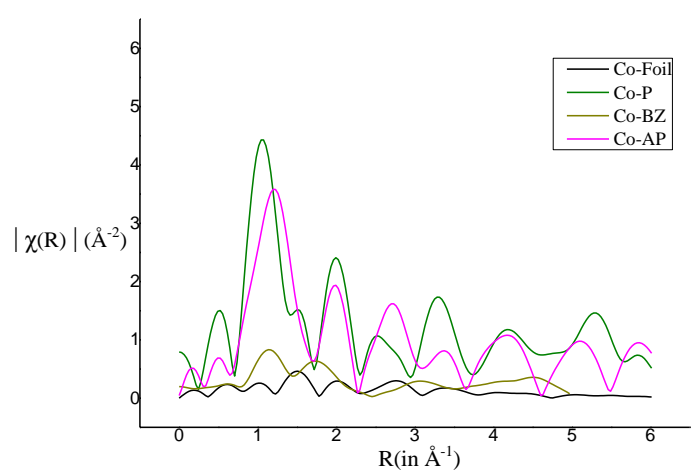

(c)

Figure2. For complexes 1-3 (a) normalized EXAFS spectra at the K-edge of Cobalt, (b) $\chi(\mathrm{k})$ vs. k spectra, and (c) Fourier transformation of $\chi(\mathrm{k}) \mathrm{vs}$. $\mathrm{k}$ spectra.

\section{ACKNOWLEDGMENT}

I would like to express my sincere gratitude to Dr Pratima Sharma for providing their valuable guidance, Dr. S N Jha, RRCAT, Indore, India for his continuous support, criticism, encouragement and invaluable assistance throughout the course of this study and Dr M. Gupta for providing facilities at DAE-CSR Indore.

\section{REFERENCES}

[1] N. Raman, Y.P. Raja, A. Kulandaisamy, "Synthesis and characterisation of $\mathrm{Cu}(I I), \mathrm{Ni}(I I), \mathrm{Mn}(\mathrm{II}), \mathrm{Zn}(\mathrm{II})$ and $\mathrm{VO}(\mathrm{II})$ Schiff base complexes derived from o-phenylenediamine and acetoacetanilide",Indian Academy of Sciences, Vol. 113, No 3, pp. 183-189, 2001.

[2] A.A. Ahmed, S.A. BenGuzzi.,A.A. EL-Hadi, "Synthesis and Characterization of Divalent Transition Metals Complexes of Schif Bases Derived From O-Phenylenediamine and Benzoylacetone and Related Species", Journal of Science and Its Applications, Vol. 1, No. 1, pp. 79-90, 2007.

[3] B. D. Cullity, " Elements of X-ray diffraction", Addison-Wesley publishing company,Inc.., 1956.

[4] A. A. Battiston, J. H. Bitter, and D. C. Koningsberger, Catal. Lett. 66, $75,2000$.

[5] D. C. Koningsberger and R. Prins, "X-ray Absorption: Principles, Applications, Techniques of EXAFS, SEXAFS, and XANES", John Wiley \& Sons, New York, 1988. 
[6] Tranchier , J.P.; Chavignon , R.; Prim , D.; Auffrant , A.; Plyta , Z.; Ros e Munch F. and Rose ,E. , Tetrahedron Letters , 41 , Issue 19 ,pp. 3607-3610,2000.

[7] Enders D.; and Shilvock, J.P. "Some recent applications of alfaamino nitrile chemistry" Chemical Society Review, issue 5, pp 359-373, 2000.

[8] A.J.M. Xavier, M. Thakur, J.M. Marie, "Synthesis and spectral characterisation of hydrazine based 14-membered octaaza macrocyclic Ni(II) complexes", Journal of Chemical and Pharmaceutical Research, Vol. 4,No. 2, pp.986-990, 2012.

[9] R. M. Levy."Bond lengths from x-ray Absorbtion- edge fine structure" Journal of chemical physics",43,1846,1965.

[10] F. W. Lytle, D. E. Sayers, E. A. "Stern.Extended x-ray-absorbtion fine -structure technique.II.Experimental practice and selected results" Physical Review. B,11 ,4825,1975 .

[11] E. A. Stern, D. E. Sayers, F. W. Lytle. "Stern.Extended x-rayabsorbtion fine -structure technique.III.Determination of physical parameters" Physical Review B , 11, 4836,1975. 